\title{
Postnatal Service Utilization and Associated Factors among Women who gave Birth in the last 12 months Prior to Study Period in Jimma Town, Southwest Ethiopia.
}

\section{Beyene Abera}

Jimma University

Fitsum Araya

Jimma University

Mulugeta Rad ( $\nabla$ mulu4915@gmail.com )

Wachemo University

Elias Ali Ysuf

Jimma University College of Public Health and Medical Sciences

Research article

Keywords: -Postnatal, Service, Utilization, Jimma, Ethiopia

Posted Date: September 17th, 2020

DOI: https://doi.org/10.21203/rs.3.rs-54730/v1

License: (9) This work is licensed under a Creative Commons Attribution 4.0 International License.

Read Full License 


\section{Abstract}

BACKGROUND: - Postnatal care is care (PNC) given to mother and new born within first 42 days of delivery. Lack of care in this period may result in disability even death of either of mother or newborn or both. The aim of this study was to determine postnatal service utilization and associated factors among women, who gave birth in the last 12 months prior to May, 2019.

METHODS: Community based cross-sectional study was conducted on 420 women who had given birth prior to May 1 to June 30, 2019(study period). The 17 kebeles of Jimma town is grouped into three similar groups based on occupation of majority of population. Three kebeles were randomly selected from each group. Data was collected using a pretested structured questionnaire. Descriptive statistic, such as frequencies, proportions and means were calculated. In bivariate logistic regression variables with p-value less than 0.25 were selected for multiple logistic analyses and multiple logistic regression was conducted. Finally significantly associated variables were declared at $p$ value less than 0.05 .

Result:-This study showed that prevalence of postnatal care utilization was $59.5 \%$. Mothers who knew at least one danger signs which comes after delivery (AOR=11.5,(95\% Cl:5.56,22.7), who attended ANC (AOR=5.4, 95\%Cl:2.7,11.3), who get counseled to attend PNC ( $\mathrm{AOR}=14.9 \% \mathrm{Cl}: 6.1,31.4)$, who attended at least primary school (AOR=2.3,95\% Cl:1.75,7.0), who did not travel more than 30 minutes to reach health facility(AOR=6.8,95\% $\mathrm{Cl} 3.4,13.6$ and those having more family size were more likely utilized postnatal service than their counterpart

Conclusions: - In this study utilization of postnatal care service was very far behind national target (which is $95 \%$ at the end of 2020 , health sector transformational plan). Awareness about danger signs, educational status of the mother, counseling to attend to attend postnatal care, distance from health facility and family size were strongly associated with PNC utilization.

\section{Background}

Postnatal care is the care given to the mother and newborn for the first six weeks after giving birth. This period is characterized by start of a new life for women and their partners as well as the beginning of new life for new born(1). It is a critical time in the lives of mothers and their babies. Majority of maternal and newborn deaths occur in the first month following delivery. Almost $50 \%$ of maternal deaths occur within the first day and 2/3 of deaths occur within first seven days of postpartum period (2). In 2013, 2.8 million newborns died in their first 30 days of life -1 million of these newborns died on the first 24 hour(3). Every year in Africa, at least 125,000 women and 870,000 newborns die in the first week after birth (4).

It is recommended that mother and new born should have four visits: first 24 hours, $48-72$ hours, days 7-14, Six weeks. Lack of care during this period might result in significant morbidity as well as mortality of both the mother or her baby or both. Every woman and newborn should be closely monitored together after childbirth; both should be checked every 15 minutes for the first 2 hours, then regularly for the next 24 hours since this period is critical time for PPH. The baby needs to be followed for respiration, 
temperature, breastfeeding, and bleeding and signs of infection from the cord . It is very important to protect women and newborns from complications after giving birth and provide important opportunity to assess the infant development to offer newborn care $(5,6)$.

PNC services utilization is affected by several factors including maternal age, educational level of the women, occupational status of women and husbands, place of delivery, mode of delivery, number of pregnancies, awareness about obstetric related danger sign, and awareness about PNC Services $(7,8)$. The 2016 EDHS data showed that among women who gave birth in last 2 years only, $17 \%$ of mother and $13 \%$ newborn had PNC within 48 hours of delivery. The data also revealed that $19 \%$ women utilized PNC within 6 weeks. This is lower than health sector transformational plan of the country, which is $95 \%$ ( 9 , 10). Eighty six percent of newborns did not get the service at all. In Africa, half of maternal deaths occurs in the first week of post-partum period; of this majority occurs in the first week after childbirth by preventable causes of maternal deaths like hemorrhage and sepsis which are prevented by good postpartum follow up (11). In Oromia region southwest Ethiopia, the proportion of mothers who utilized PNC within two days of postpartum period was only $9 \%$. This low coverage of postnatal care in our country is causing high maternal and new born morbidity and mortality. It is also challenge for planning and implementing of PNC as well as many opportunities like counseling on exclusive breast feeding, PMTCT, providing of family planning and maternal and new born care are missed(12) (10). There was no study conducted in this study area. Therefore, the aim of study was determining postnatal service utilization and associated factors in Jimma town, Ethiopia.

\section{Methods}

The study was a community based cross-sectional conducted in Jimma town, Southwest Ethiopia, located at 350 kilometers from Addis Ababa from May 1 to June 30, 2019. Jimma town has 17 kebeles and the estimated number of populations is 253,874 ; of this $47.6 \%$ are females. The town has 50,774 households and each household has an average of 5 families. There are two government hospitals, one private hospital, four health centers, 7 primary and 25 medium clinics, each kebele has health post. The study was conducted from May 1 to June 30, 2019.

Population: Randomly selected mothers who gave birth in the last 12 months prior to study period at Jimma town were included.

\section{Sample Size Determination and Sampling Procedure}

Sample size determination: Sample size was determined by sing the single population proportion formula by taking prevalence of PNC utilization $47.9 \%(\mathrm{p}=0.47)$ which is obtained from a study conducted in Halaba Kuluto, southern, Ethiopia (13), 5\% margin of error, 95\% confidence level ( $Z=1.96)$, and $10 \%$ nonresponse, a sample of 420 participants was needed. 
Sampling Procedure: Systematic random sampling was used to select the required sample from the 17 Kebeles in Jimma town: First, the Kebeles were stratified into three similar groups based on occupation of the majority of population and then three kebeles (Jiren, Ginjo and H/Mentina) were randomly selected from each stratum. Sampling frame which comprises a list of 1337 eligible mothers (who gave birth in the last 12 months) was prepared using Health Extension Workers registration and study subjects are selected with a $k$ value of three.

Inclusion criteria: All women who gave birth in Jimma town 12 months prior to study period is included in this study

Exclusion criteria: Those women who had difficulty in communication due to severe illness were excluded from the study

\section{Data collection tools}

Structured interview questionnaire was prepared and implemented after reviewing literature (13-17). The questionnaires was prepared in English then translated to Amharic and Afan Oromo to check its consistency, and then it was translated back to English by well experienced experts of both languages. Data was collected by trained two midwives and one nurse who are familiar with local language after taking 2 days training

Data processing and analysis: After checking, coding and organization of the collected the collected data, the completed questionnaires were entered into EPI-data version 3.1 and exported to Statistical Package for Social Science (SPSS) version 21. In the descriptive statistical analysis, frequencies, proportion and mean were calculated and the results of the analysis were presented in texts, tables and graphs as appropriate. Independent variables having $\mathrm{P}<0.25$ on binary logistic regression analysis were considered as candidates for multiple logistic regression analysis.

Multiple logistic regression analysis was conducted to identify factors affecting postnatal service utilization. The final model was fitted using enter variable selection methods. Before using model, fitness was checked. It was good fit. I.e. Hosmer and Lemeshow Test model adequacy p-value 0.46; overall percentage classification table is $82.2 \%$ and Nagelkerke R Square $60 \%$. Significant independent predictors were declared at $p$-value less than 0.05 , and AOR was used measure strength of association.

\section{Results}

\section{Socio Demographic Characteristic}

The total eligible sample size of 420 participated in the study which yielded a response rate about $100 \%$. The age of the participants ranged from 14-39 years with mean age of $27.4(S D=4.5)$ years and $385(91.7 \%)$ of respondents were married. Regarding the religion of the respondents, $203(48.3 \%)$ were 
Muslims followed by orthodox 137(32.6\%). Regarding to ethnicity $189(45 \%)$ were Oromos and followed by Amhara 63(15\%). Almost half of respondent's monthly income was greater than two thousand five hundred 207(49.3\%) (Table 1) at end of the document. 
Table 1

Socio-demographic characteristics of respondents $(n=420)$

\begin{tabular}{|c|c|c|c|}
\hline Variables & & Frequency & Percentage \\
\hline Age & $15-19$ & 20 & 4.7 \\
\hline \multirow[t]{4}{*}{ Category } & $20-24$ & 111 & 26.4 \\
\hline & $25-29$ & 152 & 36.1 \\
\hline & $30-34$ & 101 & 24.3 \\
\hline & $35+$ & 36 & 8.6 \\
\hline \multirow[t]{4}{*}{ Marital status } & married & 386 & 91.7 \\
\hline & single & 15 & 3.6 \\
\hline & Widowed & 11 & 2.9 \\
\hline & Divorced & 8 & 1.9 \\
\hline \multirow[t]{4}{*}{ Religion } & Protestant & 64 & 15.2 \\
\hline & Orthodox & 137 & 32.6 \\
\hline & Muslim & 203 & 48.3 \\
\hline & Catholic & 16 & 3.8 \\
\hline \multirow[t]{7}{*}{ Ethnicity } & Oromo & 189 & 45 \\
\hline & Amhara & 63 & 15 \\
\hline & Siltie & 47 & 11.2 \\
\hline & Tigray & 47 & 11.2 \\
\hline & Yam & 45 & 10.7 \\
\hline & Kafa & 20 & 4.8 \\
\hline & Dawuro & 9 & 2.1 \\
\hline \multirow[t]{4}{*}{ Educational status of mother } & unable to read and write & 45 & 10.7 \\
\hline & primary school & 123 & 29.3 \\
\hline & high school & 145 & 34.5 \\
\hline & college and above & 107 & 25.4 \\
\hline \multirow[t]{3}{*}{ Income } & $<1000$ & 53 & 12.6 \\
\hline & $1001-1500$ & 41 & 9.7 \\
\hline & $1501-2000$ & 92 & 22 \\
\hline
\end{tabular}




\begin{tabular}{|c|c|c|c|}
\hline \multicolumn{2}{|l|}{ Variables } & \multirow{2}{*}{$\begin{array}{l}\text { Frequency } \\
27\end{array}$} & \multirow{2}{*}{$\begin{array}{l}\text { Percentage } \\
6.4\end{array}$} \\
\hline & $2001-2500$ & & \\
\hline & $>2500$ & 207 & 49.3 \\
\hline \multirow[t]{3}{*}{ Parity } & 1 & 169 & 40.2 \\
\hline & $2-4$ & 241 & 57.4 \\
\hline & $5+$ & 10 & 2.4 \\
\hline \multirow[t]{4}{*}{ Educational status of husbands } & Unable to read and write & 62 & 14.8 \\
\hline & primary school & 121 & 29.5 \\
\hline & High school & 195 & 46.4 \\
\hline & College and above & 42 & 10 \\
\hline \multirow[t]{6}{*}{ Occupation of mother } & House wife & 132 & 31.4 \\
\hline & Merchant & 75 & 17.8 \\
\hline & Day laborer & 62 & 14.8 \\
\hline & Civil Servant & 83 & 19.8 \\
\hline & Private employee & 51 & 12.4 \\
\hline & Student & 17 & 4.0 \\
\hline
\end{tabular}

\section{Regarding obstetric history}

241 (57\%) of respondents were Para two - four and 169 (40.2\%) are prim Para. Three hundred twenty nine $(78.3 \%)$ of respondents gave birth vaginally.

Concerning ANC follow-up and place of delivery: - From total respondents, 333 (79.2\%) have ANC follow up. From this 190 (57\%) and 122 (37\%) respondents were having follow up at health center and hospital respectively. The rest of respondents, $21(6 \%)$ followed ANC at non-government institutions. During ANC follow up 327(98\%) were counseled to give birth at health institution.

Regarding place of delivery, $194(48 \%)$ and 182(41.2\%) mothers gave birth at hospital and Health center respectively. Home, non-governmental institutions, and health post deliveries accounted for $23(5.5 \%)$, $20(4.8 \%)$ and $1(0.2 \%)$ respectively. From all institutional deliveries, $323(81.3 \%)$ where counseled to attend PNC.

Access and Availability of PNC service: - Most of respondents were using public transport to go health facilities, and half of respondents' reported that it takes 30 minute- $1 \mathrm{hr}$. to reach to health facility (Table 2). 
Table 2

Access and Availability of PNC service for respondents $(n=420)$

\begin{tabular}{|c|c|c|c|}
\hline Variable & & Frequency & Percentage \\
\hline \multirow{4}{*}{$\begin{array}{l}\text { Means of transport usually use to go to the health } \\
\text { facility }\end{array}$} & On foot/walk & 74 & 17.6 \\
\hline & $\begin{array}{l}\text { Public } \\
\text { transport }\end{array}$ & 339 & 80.7 \\
\hline & Ambulance & 1 & 0.2 \\
\hline & Horse/Gray & 6 & 1.4 \\
\hline \multirow[t]{2}{*}{ Distance from residence to health care facility } & $\begin{array}{l}\text { Less than } 30 \\
\text { minutes }\end{array}$ & 210 & $50 \%$ \\
\hline & $30 \mathrm{~min}-1 \mathrm{hr}$ & 210 & $50 \%$ \\
\hline \multirow[t]{2}{*}{ Respect from health care provider } & No & 60 & 14.3 \\
\hline & Yes & 360 & 85.7 \\
\hline \multirow[t]{2}{*}{ Kept privacy with service providers } & No & 64 & 15.2 \\
\hline & Yes & 356 & 84.8 \\
\hline \multirow{3}{*}{$\begin{array}{l}\text { Feeling/personal views about the quality of health } \\
\text { services in the health facility }\end{array}$} & bad & 99 & 23.6 \\
\hline & good & 260 & 61.9 \\
\hline & satisfactory & 61 & 14.5 \\
\hline \multirow{2}{*}{$\begin{array}{l}\text { Self-decision to go health facility at any time to follow } \\
\text { PNC }\end{array}$} & No & 81 & 19.3 \\
\hline & Yes & 339 & 80.7 \\
\hline
\end{tabular}

\section{Awareness of respondents on postnatal care}

- Most of the respondents, 386 (91.9) knew about presence of postnatal care services at study area. About $283(67.4 \%)$ and 315(75\%) mothers knew maternal danger sign and symptoms come after giving birth and danger signs of the baby respectively (Table 3 ) 
Table 3

Awareness of postnatal care services among respondents (n 420)

\begin{tabular}{|c|c|c|c|}
\hline \multicolumn{2}{|l|}{ Variable } & Frequency & percentage \\
\hline \multicolumn{2}{|c|}{ Awareness about availability of postnatal care services } & 386 & 91.9 \\
\hline \multicolumn{2}{|c|}{ Awareness about presence of risk in post-natal period. } & 376 & 87.4 \\
\hline \multicolumn{2}{|c|}{ Respondents who knew to go health facility for PNC } & 333 & 79 \\
\hline \multirow[t]{5}{*}{ When to go to health facility } & First 24hrs & 50 & 15 \\
\hline & $\begin{array}{l}\text { As early as } 48-72 \mathrm{hrs} \text { of } \\
\text { child birth }\end{array}$ & 37 & 11.2 \\
\hline & $7-14$ days of child birth & 120 & 36 \\
\hline & At 6 weeks of child birth & 98 & 29 \\
\hline & $\begin{array}{l}\text { After 6th week (after } \\
\text { 42days) }\end{array}$ & 28 & 8 \\
\hline \multicolumn{2}{|c|}{ Awareness about maternal danger sign and symptoms } & 283 & 67.4 \\
\hline \multirow{3}{*}{$\begin{array}{l}\text { Number danger signs of mother listed by } \\
\text { respondents }\end{array}$} & 1 & 76 & 26.8 \\
\hline & 2 & 78 & 27.6 \\
\hline & 3 and above & 129 & 45.6 \\
\hline \multicolumn{2}{|l|}{ Awareness about danger signs of the baby } & 315 & 75 \\
\hline \multirow{3}{*}{$\begin{array}{l}\text { Number of danger signs of baby listed by } \\
\text { respondents }\end{array}$} & 1 & 7 & 2.2 \\
\hline & 2 & 68 & 21.6 \\
\hline & 3 and above & 240 & 76.2 \\
\hline
\end{tabular}

Factors associated with postnatal care utilization.

\section{Binary logistic regression analysis:}

Binary logistic regression analysis was done to select candidate variables for multiple logistic regression analysis. From bivariate: age, family size, marital status, income, mother education, husband education, place of delivery, means of transport, ANC attendance, distance and self-decision, knowledge about danger signs mother which comes following delivery, and counseling to follow PNC, were candidates for multivariable logistic regression analysis

\section{Multivariable logistic regression}

From multivariable logistic regression analysis, knowledge about maternal danger signs which come after delivery, Family size, ANC follow up, educational status of the mother, counseling mother to follow 
PNC after delivery and distance from health facility were significantly associated with PNC utilization.

Those mothers who knew danger signs which comes after delivery were 11.5 times (AOR 11.5, 95\% Cl: $5.8,22.7)$ more likely to utilize PNCs than mother were not aware of these post- partum complications. Similarly mothers who have ANC follow were 5.4 times (AOR $=5.4,95 \%$ Cl: $2.6,11.3$ ) more likely to utilized than who did not attend ANC during their last pregnancy.

Moreover, women who were counseled to attend PNC during their last delivery were 14 times more likely to get postnatal care service than mothers who did not counseled ( $A O R=14,95 \% \mathrm{Cl}: 6.1,31.4)$. Level of education is significantly associated with PNCS utilization, mothers who completed high school and college and above were 6.8 times and 11.7 more likely to utilize than mothers who were unable to read and write $(\mathrm{AOR}=6.8,95 \% \mathrm{Cl}: 2.2,20.94, \mathrm{AOR}=11.7,95 \% \mathrm{Cl} 3.5,38.9)$ respectively.

Family size was significantly associated with postnatal care service utilization, for one person increment in family size, PNCS utilization increased nearly one times $(\beta=0.67)$. Those mothers who live close to health facility, that means distance which takes less than 30 minutes with available transport were 6.8 times more likely to utilized than those living far from health facility $(A O R=6.8,95 \% \mathrm{Cl} 3.4,13.6)$ (Table 4). 
Table 4

significantly associated variables with PNC utilization $(n=420)$.

\begin{tabular}{|c|c|c|c|c|c|c|c|}
\hline \multicolumn{2}{|c|}{ Variables in multiple logistic regression analysis } & \multicolumn{2}{|c|}{$\begin{array}{l}\text { PNC utilization } \\
\text { status }\end{array}$} & \multirow[t]{2}{*}{ AOR } & \multicolumn{2}{|c|}{$(95 \% \mathrm{Cl})$} & \multirow[t]{2}{*}{$\begin{array}{l}\mathrm{p} \text { - } \\
\text { value }\end{array}$} \\
\hline No & Yes & Lower & Upper & & & & \\
\hline \multirow{2}{*}{$\begin{array}{l}\text { knowledge about maternal } \\
\text { danger signs }\end{array}$} & NO & 91 & 46 & 1 & & & \\
\hline & YES & 79 & 204 & 11.5 & 5.8 & 22.7 & $.001 *$ \\
\hline \multirow[t]{2}{*}{ ANC follow up } & No & 55 & 32 & 1 & & & \\
\hline & Yes & 115 & 218 & 5.4 & 2.6 & 11.3 & $.001 *$ \\
\hline \multirow{2}{*}{$\begin{array}{l}\text { Counselling to attend PNC } \\
\text { during delivery }\end{array}$} & NO & 80 & 17 & 1 & & & \\
\hline & YES & 90 & 233 & 14 & 6.1 & 31.4 & $001^{*}$ \\
\hline \multirow[t]{4}{*}{$\begin{array}{l}\text { Educational status of the } \\
\text { mother }\end{array}$} & $\begin{array}{l}\text { Unable to read } \\
\text { and read. }\end{array}$ & 31 & 14 & 1 & & & $.001 *$ \\
\hline & primary school & 62 & 61 & 2.3 & .75 & 7.01 & .140 \\
\hline & high school & 50 & 95 & 6.8 & 2.2 & 20.9 & $.001 *$ \\
\hline & $\begin{array}{l}\text { college and } \\
\text { above }\end{array}$ & 27 & 80 & 11.6 & 3.5 & 38.8 & $.001 *$ \\
\hline \multirow[t]{2}{*}{ Distance from health facility } & $\begin{array}{l}\text { Less than } 30 \\
\text { minutes }\end{array}$ & 58 & 152 & 6.8 & 3.4 & 13.6 & $0.01 *$ \\
\hline & $\begin{array}{l}\text { Greater than } 30 \\
\text { minutes }\end{array}$ & 112 & 98 & 1 & & & . \\
\hline Family size & $\beta=.669$ & & & 1.9 & 1.5 & 2.5 & $.001 *$ \\
\hline \multicolumn{8}{|c|}{$\mathrm{AOR}=1$ indicates reference group. } \\
\hline \multicolumn{8}{|c|}{$*=$ significant at $p-$ value less than $5 \%$} \\
\hline
\end{tabular}

\section{Discussion}

This study assessed PNC service utilization and associated factors among women who gave birth 12 months prior to study period. The result showed that among 420 respondents, 250 (59.5\%) utilized PNC within 6 weeks of postpartum period. This finding is higher than 19\% of national PNC service utilization coverage of EDHS2016 (9) and studies conducted in some parts of Ethiopia: Halaba kulito, southern part of Ethiopia 47.5\%(13), Jabitina district,Amhara region 20.2\%,(14) Northern Shoa 28.4\%(15), and in Lemo woreda,haddiya zone $51.4 \%(16)$. In reverse lower than study conducted in different parts the country, very far behind from national target of health sector transformational plan which is 95 percentages at the end 
of 2020 (10) and abroad country. Gondar Zuriya $66.8 \%$ (17) and $65.6 \%$ of Addis Abebe $89.2 \%(18)$. Eastern Nepal 98\% (19). This variations may be due to differences in socioeconomic status, variations in geography, time between current and previous study and access to health facilities and services. This result is comparable with study conducted Shebe Shombo district Jimma Zone $58.5 \%(20)$. This similarity may be due to similar study design and socio demographic characteristics because they are found in the same region.

Awareness about danger signs and symptoms which comes after delivery was significantly associated with PNCS utilization. This evidence is supported by study conducted at Halaba kulito(13), Lemo, Haddiya zone(16), From study conducted in Jabitina district those mothers who knew at least one danger signs which comes after delivery utilizes 4 times higher than those who fail to mention any of danger signs of pregnancy(14).

From this study, those respondents who had ANC follow up during their last pregnancy was 5 times more utilize than those who did not have ANC. Similar finding is revealed from different studies: about 6 times in lemo haddiya zone(16), 2 times in Gondar zuria district(17), 3 times in Arse Zone (20) about 9 times in shebe sombo district(20).

This study revealed that counseling mothers to follow PNC is strong predictor of PNC utilization. Those mothers counseled to attend PNC service was 14 times likely to utilize PNC than their counterparts. This study is consistent with study done in halaba(13) and 10 times Shebe Sombo(20).

Educational status of respondents have positive association with PNC utilization, those mothers who attended college and above were 11 times more utilized than mother who can't read and write; which is consistent with study done in Arsi zone(21) and Jabitina Amhara region(14).This evidence is supported by study done abroad from Ethiopia; Pakistan(11)and Nigeria(22) showing educated women empowered over decision making for utilization of health service, increased knowledge and awareness.

Utilization of PNC is affected by distance from health facility. In this study, those respondents who travel less than 30 minutes to health facility was more likely to utilize than their counterparts $(A O R=6.8)$. This finding is consistent with studies conducted in Gondar zuria distric (17). The study conducted at Arse zone showed, mothers who travel at most 1 hour to nearest health facility utilized 3 times more utilized than those who travel more than 1 hour (21).

In this study, addition in family size is associated with PNC utilization, for one addition in family size PNCS utilization is increased nearly one times; this finding is supported by study done in Belgaum of Karnataka, India(7). This indicates that mothers need help from family to utilize postnatal care services.

\section{Conclusion}

Post natal care service utilization in this study area was low. Counseling to have PNC, presence of ANC follow up during their last delivery, awareness about danger signs and symptoms which comes after

Page 12/15 
delivery, educational status of the mothers, distance from health institutions and family size were variables strongly associated with PNCS utilization.

\section{Recommendation:}

Authors recommended health professionals, health facilities. To council and appoint mothers to follow $\mathrm{PNC}$, to council on danger signs and symptoms which comes after delivery and to strengthen the existing policies and strategies to increase mother's level of awareness about PNC through education, information provision, and communication.

\section{Declarations}

\section{Ethics approval and consent to participate:}

Ethics approval was obtained from IRB of Jimma University. Letter of cooperation obtained from Jimma Zone Health Department. Verbal consent was obtained from each participants and husbands for those who are below age of 16 , after informing them about the research.

Consent for publication: Not applicable.

Availability of data and material: data used to support the findings of this study are available within the paper.

Competing Interests: there is no competing interest.

Funding: Jimma University Institute of Health examined the proposal; approved data collection, evaluated the result and funded this study.

Authors' contributions Abera B: had contributed a lot on conception, acquisition of data, analysis and interpretation of data, and Araya F, Rad M and Yesuf E had revised the paper from proposal development to manuscript preparation. All authors read and approved the final version of manuscript.

\section{Acknowledgement}

Our special thanks to data collectors, supervisors, study participants and Jimma Zone Health Department and health posts. We would also like to thank Jimma University.

\section{References}

1. Cox CTW. Postnatal Care (Puerperium). NICE Qual Stand. 2013.

2. WHO. Recommendations on Postnatal Care of the Mother and Newborn. 2013.

3. Nour NM. An introduction to maternal mortality. Rev Obstet Gynecol]. 2008; 1(2).

4. Debra, Bick. Christine MacArthur, Heather Winter. Postnatal Care. 2009. 
5. World Health Organization. Counseling For Maternal and Newborn Health Care. A Hand book for building skills 2013 .

6. WHO. Postnatal Care for Mothers and Newborns Highlights from the World Health Organization 2013 Guidelines. USAID from Am People. 2015: 1-8.

7. Paudel $D$, Nilgar $B$, Bhandankar M. Determinants of postnatal maternity care service utilization in rural Belgaum of Karnataka, India: A community based cross-sectional study. Int J Med Public Heal. 2014;4(1):96.

8. WHO. Level\& Trend in Child Mortality]. 2014.

9. Central Statistical Agency (CSA) [Ethiopia] and ICF. EDHS 2016. Ethiopia: Addis Ababa; 2016.

10. The Federal Democratic Republic of Ethiopia Ministry of Health, Health Sector Transformation Plan 2015.

11. Yunus A, Iqbal S, Munawar R, Zakar R, Mushtaq SK, Sadaf F, et al. Determinants of Postnatal Care Services Utilization in Pakistan- Insights from Pakistan Demographic and Health Survey (PDHS) 2006-07. Middle-East J Sci Res. 2013;18(10):1440-7.

12. Lawn JE, Cousens SZ. Lancet Neonatal Survival Steering Team. 4 million neonatal deaths: when? Where? Why? Lancet. 2005;365:891-900.

13. Abebo TA, Tesfaye DJ. Postnatal care utilization and associated factors among women of reproductive age Group in Halaba Kulito Town, Southern. Arch Public Heal. 2018; 1-10.

14. Yinager Gebeyehu workineh. Desta Aregawi hailu.Factors affecting utilization of postnatal care service in jabitena district, Amhara region, Ethiopia,Science. J Public Health. 2014;2(3):169-76. doi:10.11648/j.sjph.20140203.15.

15. Mohammed Akibu, Wintana Tsegaye,Tewodros Megersa, and SodereNurgi.Prevalence and Determinants of Complete Postnatal Care Service Utilization in Northern Shoa, Ethiopia,2018,Journal of Pregnancy Volume 2018, Article ID 8625437, 7 pages.

16. https://doi.org/10.1155/2018/8625437.

17. Belachew T, Taye A. Postnatal Care Service Utilization and Associated Factors among Mothers in Lemo Woreda, Ethiopia. J Women's Heal Care. 2016;5(3).

18. Tesfahun F, Worku W, Mazengiya F, Kifle M. Knowledge. Perception and Utilization of Postnatal Care of Mothers in Gondar Zuria District, Ethiopia: A Cross-Sectional Study. Matern Child Health J. 2014;18(10):2341-51.

19. Senait Birhanu,Sr Yeshi asefa, Birhanu Wordofa Giru. Prevalence of postnatal care service utilization and associated factors among women who gave birth and attending immunization in selected government health centers in Addis abebe, Ethiopia .2016.

20. Ishwar sharman paudel,sailesh bhattarhai, Rajan Bikram. Post natal service utilization among mothers in Estern region of Nepal, journal of Novel medical college.

21. Fantaye, Chemir. Melkamu Gelan and Makeda Sinaga. Postnatal Care Service Utilization and Associated Factors among Mothers Who Delivered in Shebe Sombo Woreda, Jimma Zone, Ethiopia, 
DOI: $10.23937 / 2474-1353 / 1510078$.

22. Ashenafi kifle, Sena L, Jarso H. Determinants of postnatal care service utilization, Amiga district, Arsi zone, southeast Ethiopia. Care control study, journal of women health care, 2018.

23. 10.11604 /pamj.2015.21.321.6527

Tukur Dahiru OM, Oche, Determinants of antenatal care, institutional delivery and postnatal care services utilization in Nigeria, The Pan African Medical Journal.2015;21:321.

doi:10.11604/pamj.2015.21.321.6527.

\section{Supplementary Files}

This is a list of supplementary files associated with this preprint. Click to download.

- EnglishVersionQuestionnaire.docx 